\title{
Design and Analysis of Sisal Filled Glass Epoxy Composite Leaf Spring
}

\author{
Mr. Y. S. More ${ }^{1}$, Prof. D. S. Chaudhari ${ }^{2}$ \\ ${ }^{I}(P G$ Student, Department of Mechanical Engineering, GES's R. H. Sapat COE, Nashik, India) \\ ${ }^{2}$ (Asst. Prof., Department of Mechanical Engineering, GES's R. H. Sapat COE, Nashik, India)
}

\begin{abstract}
Automobile companies are showing interest in reducing the weight of vehicle by replacing the steel by GFRC for increasing the fuel economy and performance. The Natural Fiber composites are the excellent alternative for the GFRC due to lightweight compared to steel and low cost as well as good elastic strain energy storage capacity. The sisal fiber is a naturally Biodegradable material. The sisal fiber is having high strength to weight ratio compared to steel. The present work focuses on designing of leaf spring for Light commercial vehicle made of Sisal Fiber Reinforced Composite. Fabrication method used is Hand lay-up method. The work carries analytical results, finite element results and experimental results. The experimental testing was performed on UTM and Ansys is used for FEA. Deflection and Stresses were carried analytically and experimentally. NFRC leaf spring has stresses with in the limit for the desired Sisal Fiber Reinforced Composite.
\end{abstract}

Keywords: Composites, Leaf Spring, Natural Fibers, Sisal.

\section{Introduction}

The leaf spring suspension is a very crucial part for weight reduction due to its appreciable share in the unsprung mass of vehicle near about $20 \%$ of unsprung mass. The material with better performance and design of leaf spring with optimized parameters can lead to mass reduction [1]. The natural fibers are better than the synthetic fibers from cost comparative. The mechanical properties of synthetic fiber such as GF and CF are much higher than natural fibers such as sisal, jute and cotton. The synthetic fibers are non-biodegradable and difficult to recycle where as natural fibers are biodegradable, environment friendly and easy to recycle [2]. Leaf spring with composite material shows better load carrying capacity than conventional steel leaf spring for same deflection [3]. The researchers have shown keen interest towards the green composites and duty for society for better environment friendly and economical replacement of synthetic polymer composites [4]. Study reveals that the reduction of weight by $10 \%$ enhances the mileage near about 7\% depending on the car type and drive cycle and also the decrease in $\mathrm{CO}_{2} / \mathrm{km}$ [5].

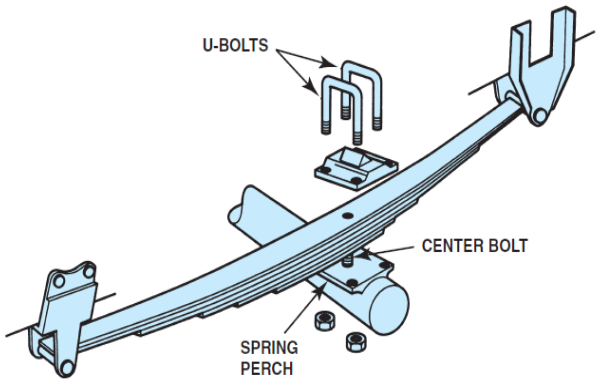

Fig. 1: Multi Leaf Spring assembly

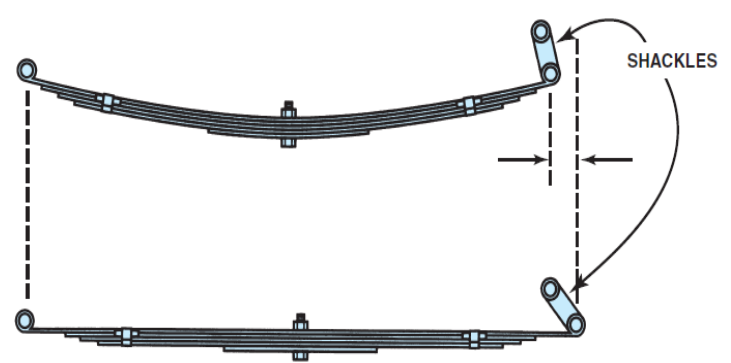

Fig. 2: When a leaf spring is compressed, the spring flattens and becomes longer. The shackles allow for this lengthening.

\section{Literature Review}

Most of the work has been done in the field of replacing the steel leaf spring with glass fiber composites [6-13, 16]. Prediction of fatigue life is enhanced due to use of Life Data Analysis technique for composite and steel multi-leaf spring by Senthil Kumar and Vijayarangan [14]. End joint with bonded nature are better than the bolted end joints for stress concentration and delamination [15]. Groundnut shell powder is used for composite and tested for thermal and mechanical properties, which shows good result with 15 wt $\%$ composition [17]. Treatment performed on jute fiber has shown better creep behaviour than untreated fiber composite [19]. Increase in percentage of jute and glass fiber in composite shows improvement in tensile 
strength and marginal improvement in flexural strength. Loss of mass is more above specific temperature [20]. Selection of matrix plays important role in adhesion of fiber and matrix, which has very strong impact on properties like tensile, compression and flexural [21]. RHFGE composite is a good alternative to GFEC [22-24]. Red mud is used along with bamboo fiber and comparative study with GEHC is done for erosion behaviour [25]. Repair of aeronautic structures have studied with application of GEC, CEC and combination of both composite [26].

\section{Problem Identification}

The Literature survey briefs about most of research work is done on

1) Leaf spring weight reduction with concentration on changing material.

2) Most of researchers have taken the composite as an only alternative. Instead of any other grade of steel or Natural fiber reinforced composites.

3) NFRGEC as a biodegradable material for leaf spring is not focused by many researchers. This research gap is used in defining and formation of problem statement and objective of project.

\section{Objectives}

1) To develop a composite material from sisal fiber particulate for application of leaf spring.

2) To test the specimen as per ASTM standards.

3) Determine through structural analysis the Load vs. Deflection of Sisal Fiber Reinforced Composite Leaf Spring.

\subsection{Materials}

\section{Methodology}

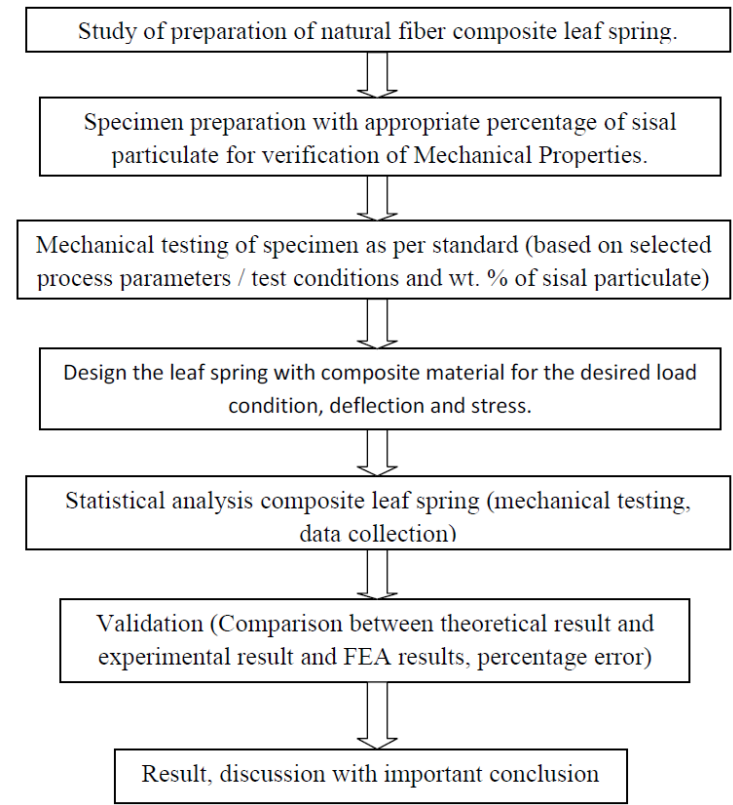

\section{Experimental For Specimen}

The combination of \% mass of GF, SF and Resin in each composite is shown in table 1.

Table 1: Percentage by mass of samples

\begin{tabular}{|l|c|c|c|}
\hline \multirow{2}{*}{ Composites } & \multicolumn{3}{|c|}{ Percentage by mass of samples } \\
\cline { 2 - 4 } & $\begin{array}{c}\text { Glass Fiber } \\
\text { (\% in mass) }\end{array}$ & $\begin{array}{c}\text { Sisal Fiber } \\
\text { (\% in mass) }\end{array}$ & $\begin{array}{c}\text { Epoxy Resin } \\
\text { (\% in mass) }\end{array}$ \\
\hline Sample 1 & 55 & 0 & 45 \\
\hline Sample 2 & 45 & 10 & 45 \\
\hline Sample 3 & 30 & 30 & 40 \\
\hline
\end{tabular}

Epoxy resin: The epoxy resin (HSC 7251) and the hardener (HSC 8221) are supplied by Hindustan Speciality Chemicals, Mumbai.

Sisal fiber: The sisal fibers are sourced by Tokyo Engineering.

Glass fiber: The glass fibers used in fabric form of Owens Corning supplied by local supplier were: Grammage $-365 \mathrm{~g} / \mathrm{m}^{2}$. 
A wooden mould is used having dimensions as $12 \times 8 \times 1$ inch $^{3}$ and Hand-lay-up method and compression moulding is used for preparing the specimen. For easy removal of specimen after moulding, the mould releasing spray is used before initiation of process. The epoxy resin and hardener are mixed in ratio of 5:1 as per properties. The fibers have a tendency to cluster and mesh together when mixed with matrix. To avoid the issue with fibers and matrix uniform mixing special care is taken. Fibers are first dipped in the matrix and then lay down in the mould. After proper proportions of GF, SF and matrix the mould is pressed by $30 \mathrm{kgf}$ force for $12 \mathrm{~h}$ before it removed from the mould. The specimen is kept for 24 hours in the air for post cure. Specimens of suitable dimension are cut using a diamond cutter for physical characterization and mechanical testing. Utmost care has been taken to maintain uniformity and homogeneity of the composite.

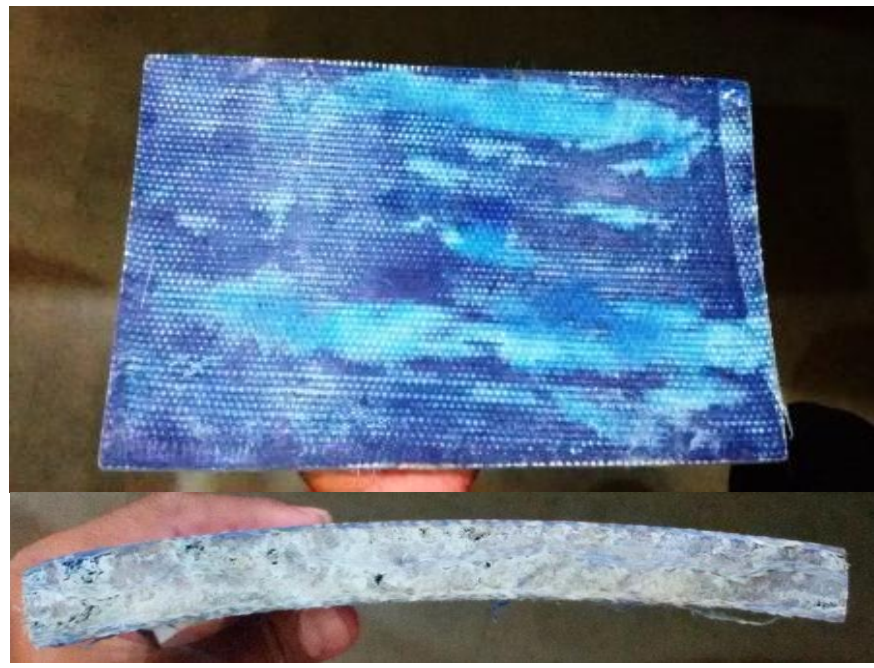

Fig. 3: Sisal Fiber reinforced composite specimen

\subsection{Test of density, tensile, compression and flexural properties}

\subsubsection{Mechanical studies}

ASTM standards are used for various mechanical test performed on specimen prepared as sample 1, sample 2 and sample 3 . For all the tests the temperature is $23{ }^{\circ} \mathrm{C}$ in the specimen and relative humidity is $50 \%$. The tensile test is performed according to ASTM D638 on Universal Testing machine as shown in fig. 4. The compression test was performed according to ASTM D695 as shown in fig. 6. The bending test was performed according to ASTM D790 on Universal Testing machine as shown in fig. 5. The impact test for the sample dart drop was performed according to ASTM E 23 [20].

Table 3 shows the findings of the tests performed on the specimen.

\subsubsection{Density}

The theoretical density of composite materials in terms of weight fraction can easily be obtained as for the following equations given by Sandhyarani Biswas [25].

$$
\rho c t=\frac{1}{\left(\frac{W g}{\rho g}\right)+\left(\frac{W m}{\rho m}\right)}
$$

Where, $\mathrm{W}$ and $\rho$ represent the weight fraction and density, respectively. The suffix $\mathrm{g}, \mathrm{m}$ and ct stand for the fiber, matrix and the composite materials, respectively.

The composites under this investigation consists of three components namely matrix, glass fiber and sisal filler. Hence the modified form of the expression for the density of the composite can be written as

$$
\rho c t=\frac{1}{\left(\frac{W g}{\rho g}\right)+\left(\frac{W m}{\rho m}\right)+\left(\frac{W s}{\rho s}\right)}
$$

Table 2: Measured and theoretical densities of the Sisal filled glass-epoxy composites

\begin{tabular}{|c|c|c|c|}
\hline Composites & $\begin{array}{c}\text { Measured density } \\
(\mathrm{g} / \mathrm{cc})\end{array}$ & $\begin{array}{c}\text { Theoretical density } \\
(\mathrm{g} / \mathrm{cc})\end{array}$ & $\begin{array}{c}\text { Volume fraction of voids } \\
(\%)\end{array}$ \\
\hline Glass-epoxy + 0 wt.\% Sisal Fibers & 1.69 & 1.698 & 0.4711 \\
\hline Glass-epoxy + 10 wt.\% Sisal Fibers & 1.4 & 1.410 & 0.7092 \\
\hline Glass-epoxy + 30 wt.\% Sisal Fibers & 1.26 & 1.290 & 2.3256 \\
\hline
\end{tabular}




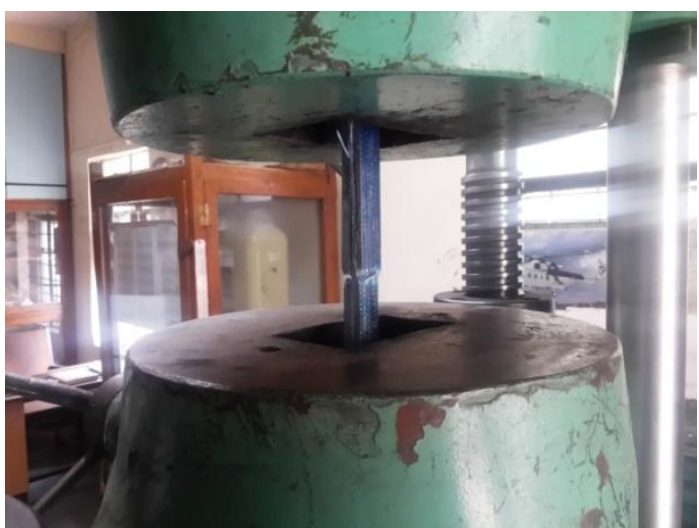

Fig. 4: Tensile Test

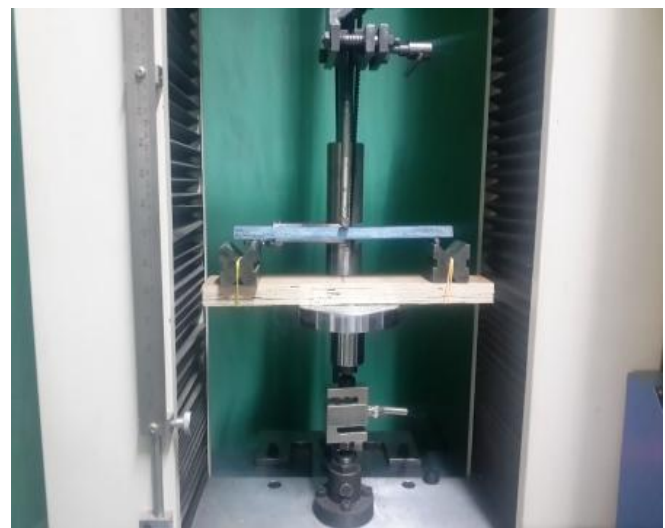

Fig. 5: Flexural Test

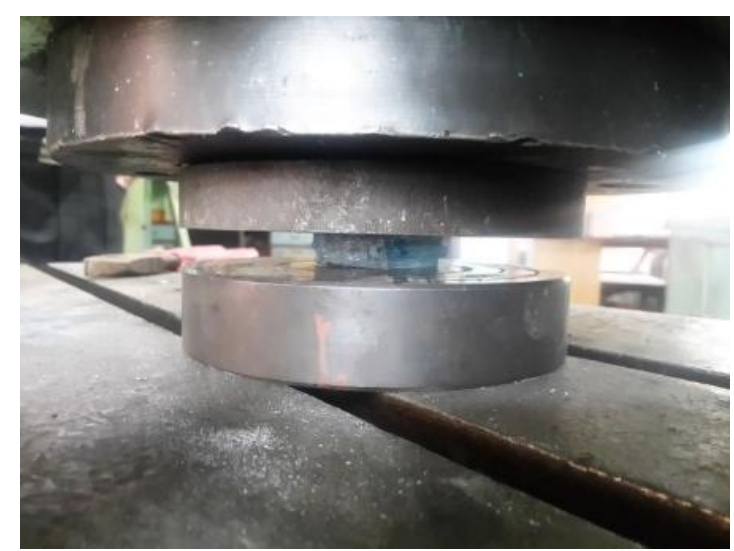

Fig. 6: Compression Test

Table 3: Test results for the Sisal filled glass-epoxy composites specimen

\begin{tabular}{|c|c|c|c|c|}
\hline Composites & Tensile Strength $\left(\mathrm{N} / \mathrm{mm}^{2}\right)$ & Compressive Strength $\left(\mathrm{N} / \mathrm{mm}^{2}\right)$ & Flexural Strength $\left(\mathrm{N} / \mathrm{mm}^{2}\right)$ & Shear Strength $\left(\mathrm{N} / \mathrm{mm}^{2}\right)$ \\
\hline Sample 1 & 287 & 317 & 127.49 & 89.49 \\
\hline Sample 2 & 165 & 237 & 164.85 & 10.25 \\
\hline Sample 3 & 87 & 122 & 72.80 & 32.62 \\
\hline
\end{tabular}

\section{Problem Formulation}

Here Weight and initial measurements of four wheeler "TATA ACE" Light commercial vehicle is taken in to consideration [1].

Weight of vehicle $=700 \mathrm{~kg}$

Maximum load carrying capacity $=1000 \mathrm{~kg}$

Gross vehicle weight $=700+1000=1700 \mathrm{~kg}$;

Taking factor of safety (FS) $=2$

Acceleration due to gravity $(\mathrm{g})=9.81 \mathrm{~m} / \mathrm{s} 2$

Therefore; Total Weight $=1700 * 9.81=16677 \mathrm{~N}$

Since the vehicle is 4 -wheeler, a single leaf spring corresponding to one of the wheels takes up one fourth of the total weight.

$16677 / 4=4169 \mathrm{~N}$,

But $2 \mathrm{~F}=4169 \mathrm{~N} . \quad \mathrm{F}=2085 \mathrm{~N}$.

Span length, $2 \mathrm{~L}=860 \mathrm{~mm}, \quad \mathrm{~L}=430 \mathrm{~mm}$.

\subsection{Analytical Methodology of Leaf spring:}

Table 4: Design parameters of leaf spring

\begin{tabular}{|c|l|c|}
\hline Notation & \multicolumn{1}{|c|}{ Parameter } & Value \\
\hline $\mathrm{nf}$ & Number of extra full-length leaves for steel leaf spring & 1 \\
\hline $\mathrm{ng}$ & Number of graduated length leaves including master leaf for steel leaf spring & 2 \\
\hline $\mathrm{nf}$ & Number of extra full-length leaves for SFRC leaf spring & 3 \\
\hline $\mathrm{ng}$ & Number of graduated length leaves including master leaf for SFRC leaf spring & 0 \\
\hline $\mathrm{n}$ & Total number of leaves & 3 \\
\hline $\mathrm{b}$ & Width of each leaf (mm) & 60 \\
\hline $\mathrm{L}$ & Length of the cantilever or half the length of semi-elliptic spring (mm) & 430 \\
\hline
\end{tabular}




\begin{tabular}{|c|l|c|}
\hline $\mathrm{y}$ & Camber & 115 \\
\hline $\mathrm{t}$ & Thickness of each leaf for steel $(\mathrm{mm})$ & 8 \\
\hline $\mathrm{t}_{1}$ & Thickness of each leaf for Natural Fiber composite $(\mathrm{mm})$ & 20 \\
\hline $\mathrm{W}$ & force applied at the end of the spring $(\mathrm{N})$ & 2085 \\
\hline
\end{tabular}

Deflection and stress of the spring is can be determined by equation (3) and (4).

$$
\begin{array}{ll}
\text { Deflection } & \delta=\frac{12 \mathrm{WL}^{3}}{\mathrm{Ebt}^{3}(3 \mathrm{nf}+2 \mathrm{ng})} \\
\text { Stress } & \sigma=\frac{6 \mathrm{WL}}{\mathrm{nbt}^{2}}
\end{array}
$$

\section{Finite Element Analysis}

The aim of this analysis is to study the multi-leaf steel leaf spring and verification of the results within the desirable limits. ANSYS 12.0 software is used to analyze the stresses by performing static analysis for the given leaf spring specification and to determine the deflection in leaf springs. Analysis involves discretization called meshing, boundary conditions, loading.

\subsection{Meshing}

Meshing involves division of the entire of model into small pieces called elements. It is convenient to select the free mesh because the leaf spring has sharp curves, so that shape of the object will not alter. The element edge length is taken as $4 \mathrm{~mm}$. The numbers of elements are taken 30000 and the total numbers of nodes are 148741. The figure 7 shows the mesh model of multi leaf spring.

\subsection{Boundary Conditions}

The front eye of the leaf spring is coupled directly with a pin to the frame so that the eye can rotate freely about the pin but no translation is occurred. The rear eye of the spring is connected to the shackle which is a flexible link the other end of the shackle is connected to the frame of the vehicle. The leaf spring is totally fixed at the centre with the help of bottom plate to the axel of vehicle. The force $4169 \mathrm{~N}$ applied at the center of the leaf spring bottom surface. One eye of the leaf spring has the flexibility to slide along the Z-direction when load applied on the spring and also it can rotate about the pin in X- direction. The link oscillates during load applied and removed. So the displacement at the both eye is constrained along the $\mathrm{X}$ and $\mathrm{Y}$ directions.

Figure 8 and figure 9 shows the deflection and stress induced in the steel multi leaf spring for the rated load respectively. Figure 10 and figure 11 shows the deflection and stress induced in the sisal fiber reinforced composite multi leaf spring for the rated load respectively.

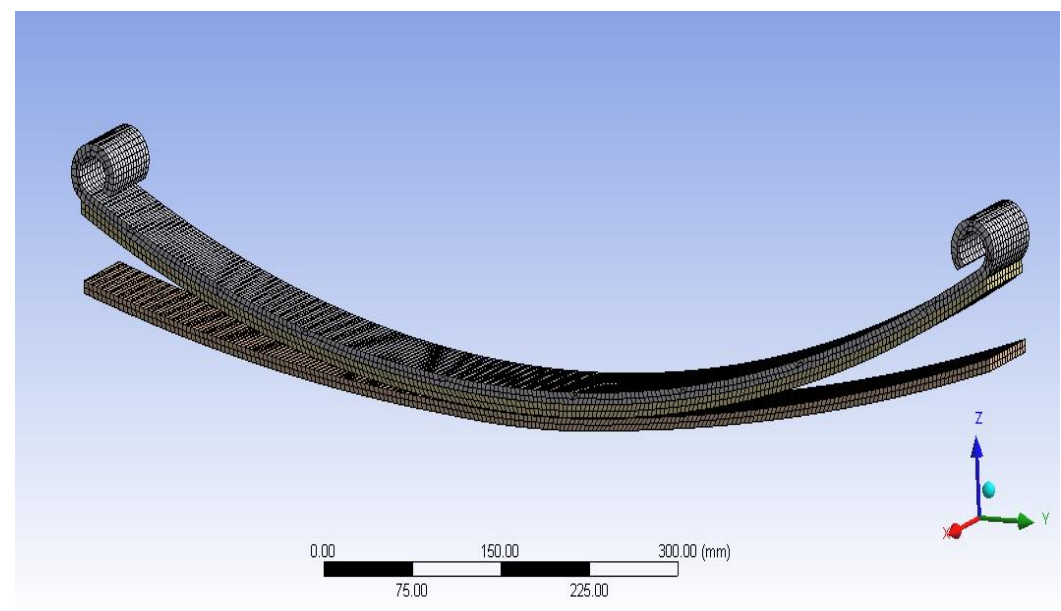

Fig. 7: Mesh Model of Leaf Spring 


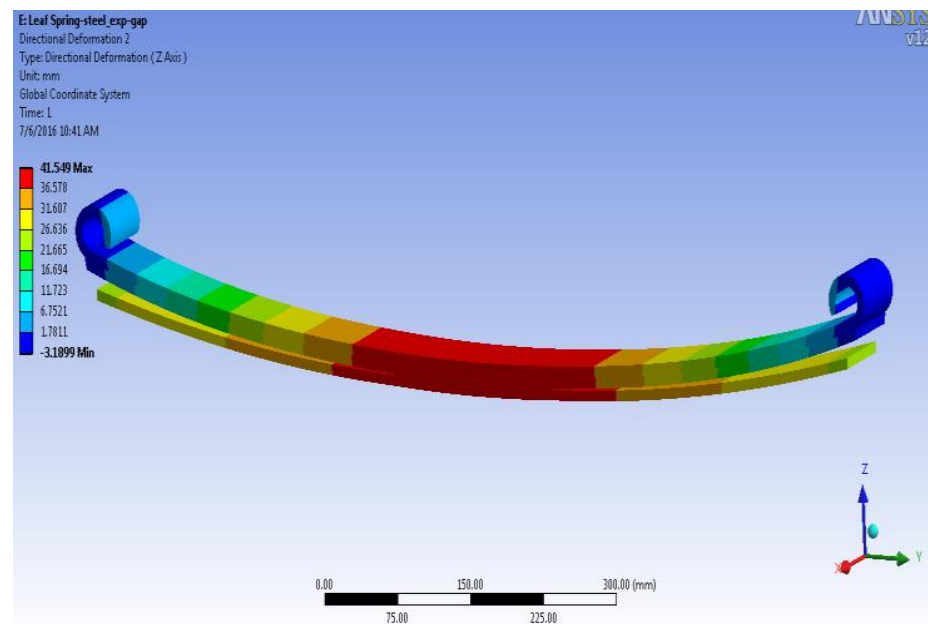

Fig. 8: Total deformation of steel leaf spring at rated load

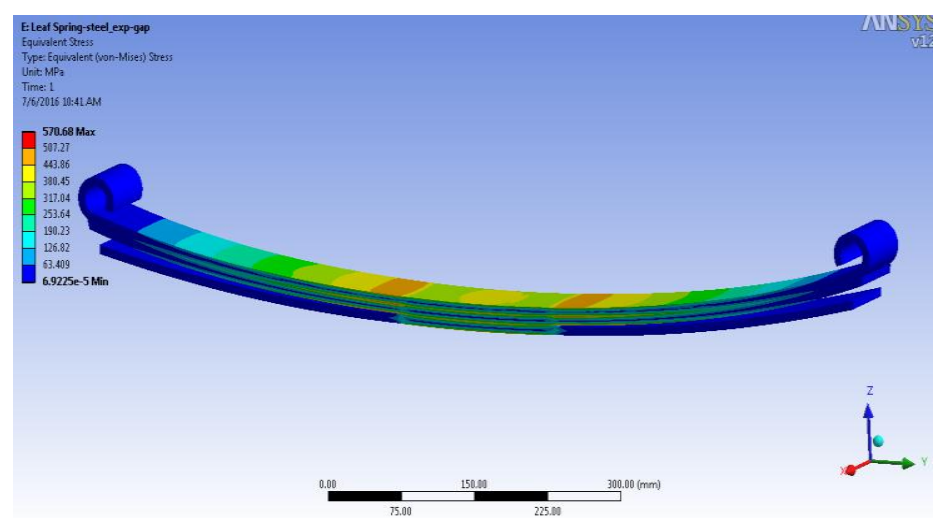

Fig. 9: Bending stress in steel leaf spring at rated load

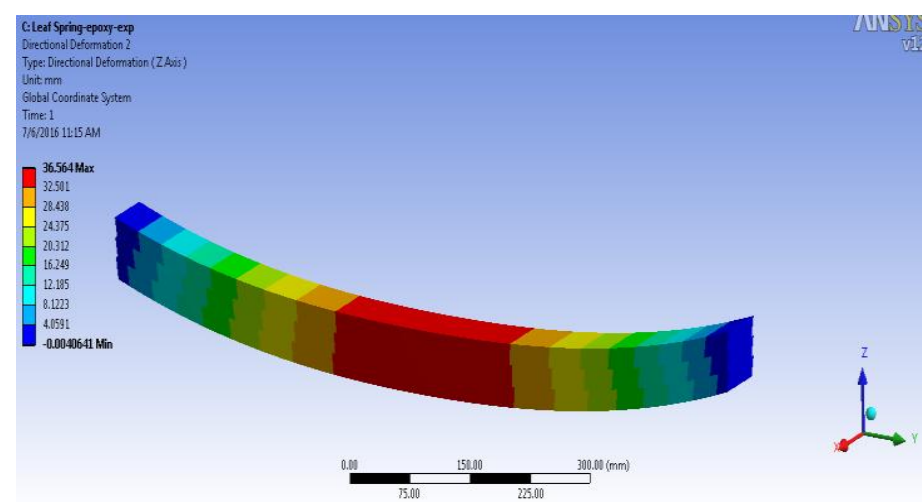

Fig. 10: Total deformation of SFRC leaf spring at rated load

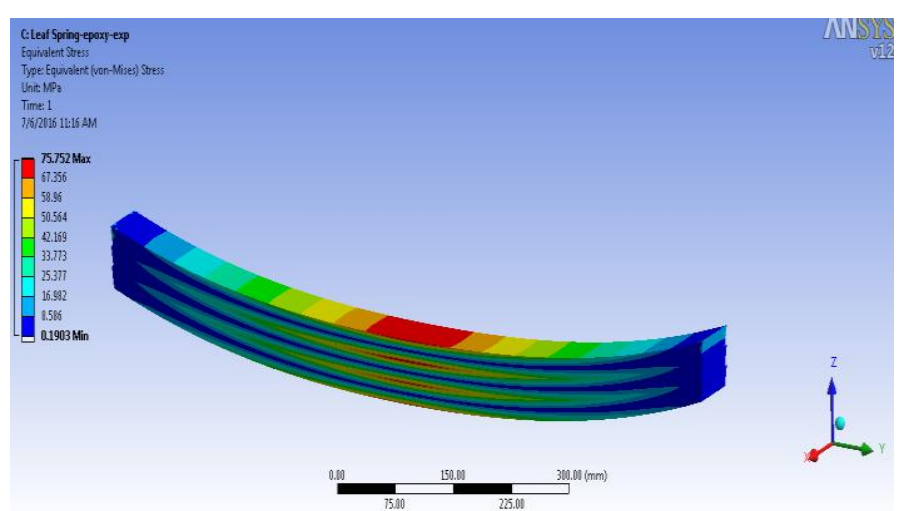

Fig. 11: Bending stress in SFRC leaf spring at rated load 


\section{Experimental For Composite Leaf Spring}

\subsection{Fabrication of composite leaf spring:}

The percentage ratio of glass fiber, sisal fiber and epoxy is selected is from sample 2 . The results for sample 2 are comparatively good for leaf spring application. The composite leaf springs are made by conventional hand-lay-up technique followed by light compression moulding technique. A wooden mould as shown in fig. 12 is used. A releasing agent (silicon spray) used to facilitate easy removal of the composite from the mould after curing. The low temperature curing epoxy resin and corresponding hardener are mixed in a ratio of 5:1 by weight as recommended. The mix is stirred manually to disperse the fibers in the matrix. Care is taken to ensure a uniform sample since fibers have a tendency to clump and tangle together when mixed. The cast of each composite is cured under a load of about $30 \mathrm{~kg}$ for $12 \mathrm{~h}$ before it removed from the mould. Then this cast is post cured in the air for another $24 \mathrm{~h}$ after removing out of the mould as shown in fig. 13. The product after curing is shown in fig.14. The leaf spring is in raw form is then finished with desired dimensions using diamond cutter. A coating is provided on the leaf spring for better finish. Fig. 15 shows the finished leaf springs after coating.

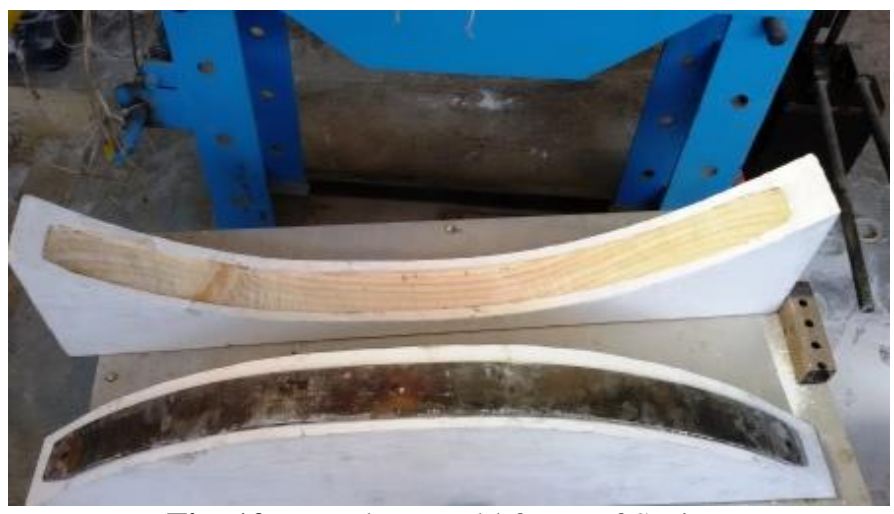

Fig. 12: Wooden mould for Leaf Spring

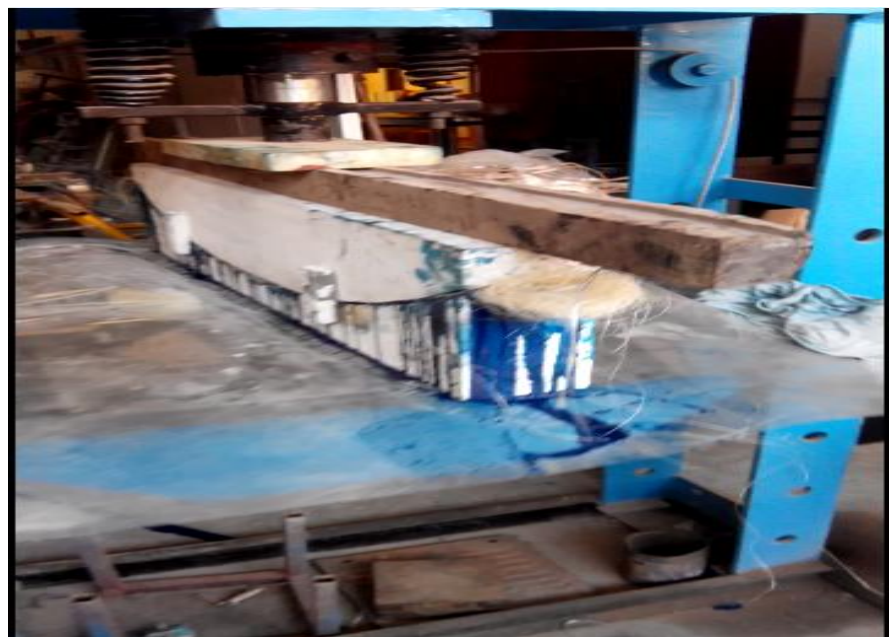

Fig. 13: Light compression moulding of composite Leaf Spring.

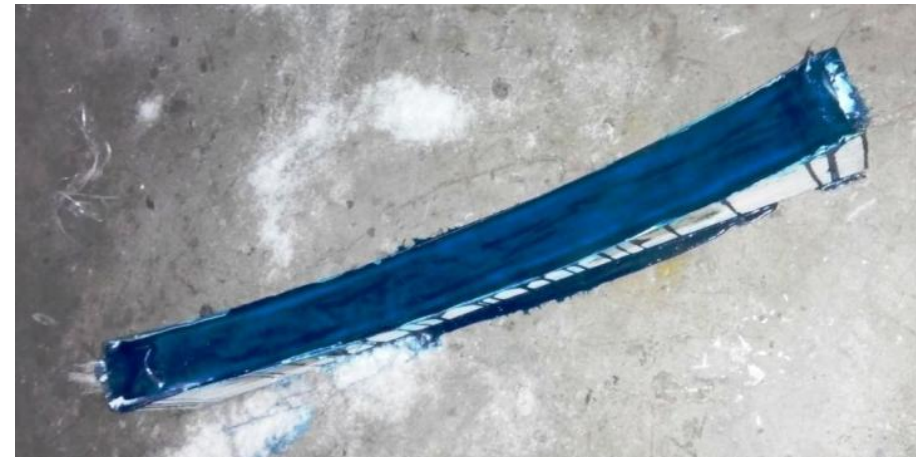

Fig. 14: Raw leaf spring after curing 


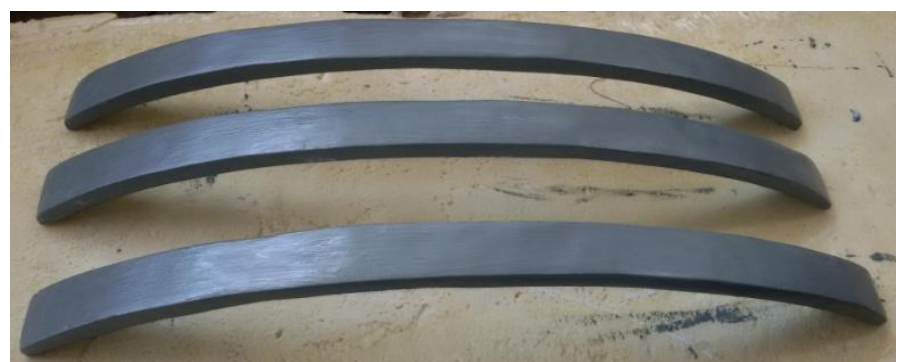

Fig. 15: SFR Composite Leaf Spring after coating

\subsection{Mechanical testing of composite leaf spring:}

The multi leaf composite spring is tested for rated load on Universal testing machine as shown in fig. 16. The test is carried out for load from $0 \mathrm{~kg}$ to $450 \mathrm{~kg}$ with interval of $50 \mathrm{~kg}$. The respective deflection is measured for every interval.

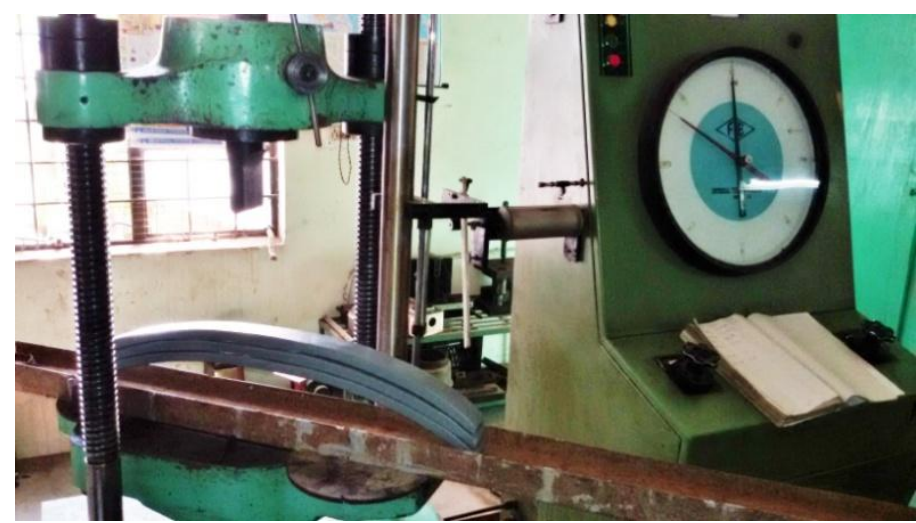

Fig. 16: Testing of SFRC Leaf Spring

\section{Result And Discussion}

From the results of specimen for the Mechanical test as shown in table 2, it is observed that when the percentage of Sisal fiber increases the density of the composite material decreases. The tensile strength of the composite drastically reduces as percentage of natural fiber increases. It is observed that the flexural strength of the sample 2 is more than sample 1 and reduces for sample 3, for the sisal fiber mass percentage of $11 \%$ gives better flexural strength than pure glass fiber reinforced composite. The flexural strength again decreases for $30 \%$ sisal fiber. As shown in table 3, the shear strength of sample 3 is more than sample 2, which indicates that increased percentage of sisal fiber increases the shear strength.

From the results of FEA of steel leaf spring, it is seen the displacement of leaf spring is $41.549 \mathrm{~mm}$ which is well below the camber length of leaf spring shown in fig.8. It is seen that the maximum bending stress is about $570.68 \mathrm{MPa}$, which is less than the yield strength of the material shown in fig. 9. The FEA results are compared with the theoretical results and found that the theoretical result and FEA result are nearer to each other as shown in table 5.

Table 5: Comparison between theoretical and ANSYS results of conventional steel leaf spring

\begin{tabular}{|l|c|c|}
\hline \multicolumn{1}{|c|}{ Parameter } & Theoretical Results & FEA Results \\
\hline Load, N & 4169 & 4169 \\
\hline Bending Stress, $\mathrm{MPa}$ & 466.95 & 570.68 \\
\hline Total Deflection, mm & 46.25 & 41.549 \\
\hline
\end{tabular}

After that the multi leaf spring with E-Glass/Epoxy material is analyzed in ANSYS-12 with $20 \mathrm{~mm}$ thickness and same boundary condition as that of conventional leaf spring, showing bending stress and deflection under load in figures $10 \& 11$. The comparison between theoretical, experimental and FEA results are as shown in table 6.

Table 6: Comparison between theoretical, experimental and ANSYS results of SFRC leaf spring.

\begin{tabular}{|l|c|c|c|}
\hline Parameters & Theoretical Results & Experimental Results & FEA Results \\
\hline Load, N & 4169 & 4169 & 4169 \\
\hline Bending Stress, MPa & 74.71 & ---- & 75.75 \\
\hline Total Deflection, mm & 33.13 & 31.5 & 36.56 \\
\hline
\end{tabular}


The result shows that the Sisal fiber reinforced composite leaf spring having less deflection compare to conventional steel leaf spring. The stress induced in the SFRC leaf spring is well within the strength of the test specimen for sample 2. The conventional multi leaf spring weights about $9.000 \mathrm{~kg}$ whereas the SFRC multi leaf spring weighs only $5.500 \mathrm{~kg}$. Thus the weight reduction of $35.00 \%$ is achieved. Totally it is found that the SFRC composite leaf spring is the better that of steel leaf spring.

\section{Conclusion}

In the present work, a steel leaf spring was replaced by a sisal fiber reinforced composite leaf spring due to high strength to weight ratio for the same load carrying capacity and stiffness as that of steel leaf spring.

A semi-elliptical multi leaf spring is designed for a four wheel automobile and replaced with a composite multi leaf spring made of SFRC composites.

Under the same static load conditions the stresses and the deflection in leaf springs are found with great difference. Stresses and deflection in SFRC composite leaf springs is found out to be less as compared to the conventional steel leaf springs.

All the FEA results and experimental results are compared with the theoretical results and it is found that they are within the allowable limits and nearly equal to the theoretical results.

A comparative study has been made between steel and composite leaf spring with respect to strength and weight. Composite leaf spring reduces the weight by $35.00 \%$ for SFRC composite.

SFRC composite leaf spring can be suggested for replacing the steel leaf spring both from stiffness and stress point of view.

Totally it is found that the SFRC composite multi leaf spring is the better that of steel multi leaf spring. Therefore, it is concluded that composite multi leaf spring is an effective replacement for the existing steel multi leaf spring in vehicles.

\section{References}

[1] Edward Nikhil Karlus, Rakesh L. Himte, Ram Krishna Rathore, "Optimization of mono parabolic leaf spring," international journal of advances in engineering \& technology, ISSN: 22311963, Vol. 7, Issue 1, pp. 283-291, Mar. 2014.

[2] k. john and s. venkata naidu, "Sisal Fiber/Glass Fiber Hybrid Composites: The Impact and Compressive Properties," Journal of Reinforced Plastics and Composites, DOI: 10.1177/0731684404035270, 0731-6844/04/12 1253-6, Vol. 23, No. 12/2004.

[3] S. Rajesh and G. B. Bhaskar, "Experimental Investigation on Laminated Composite Leaf springs Subjected to Cyclic Loading," International Journal of Engineering and Technology (IJET), ISSN : 0975-4024, Vol. 6 No 1 Feb-Mar 2014.

[4] Jan Willem Van Der Wiel "Future Of Automotive Design \& Materials Trends And Developments In Design And Materials"

[5] Subhash Chandrabose, C. Thamotharan, P. Naveenchandran and R. Anbazhagan, "Design Optimization and Analysis of a Parabolic Leaf Spring,” Middle-East Journal of Scientific Research 20 (11): 1590-1596, ISSN 1990-9233

[6] Ravi Kumar V, R. LalithaNarayana, Ch. Srinivas "Analysis of Natural Fiber Composite Leaf Spring" International Journal of Latest Trends in Engineering and Technology (IJLTET), ISSN: 2278-621X, Vol. 3 Issue 1 September 2013

[7] Jadhav Mahesh V, ZomanDigambar B, Y R Kharde, R RKharde, “Performance Analysis of Two Mono Leaf Spring Used For Maruti 800 Vehicle", International Journal of Innovative Technology and Exploring Engineering (IJITEE), ISSN: 2278-3075, Volume-2, Issue-1, December 2012

[8] B. Raghu Kumar, R. Vijaya Prakash, N. Ramesh, "Static analysis of mono leaf spring with different composite materials", Journal of Mechanical Engineering Research Vol. 5(2), pp. 32-37, February 2013

[9] D. Abdul Budan, T.S. Manjunatha," Investigation on the Feasibility of Composite Coil Spring for Automotive Applications", International Journal of Mechanical, Aerospace, Industrial, Mechatronic and Manufacturing Engineering Vol:4, No:10, 2010

[10] Akhil Mehndiratta1, Nand Kishore Singh2, Kalyan Kumar Singh, "Analysis of GFRP Leaf Spring” IJMER, ISSN: 2249-6645, Vol. 5, Iss. 5, May 2015

[11] H. A. Al-Qureshi, "Automobile leaf spring from composite materials", Journal of materials processing technology, 118 (2001) 58 61

[12] Mahmood M. Shokrieh, DavoodRezaei, “Analysis and optimization of a composite leaf spring”, Composite Structures 60 (2003) $317-325$

[13] ErolSancaktar at, Mathieu Gratton, "Design, analysis, and optimization of composite leaf springs for light vehicle applications", Composite Structures 44 (1999) 195-204

[14] Mouleeswaran SENTHIL KUMAR, Sabapathy VIJAYARANGAN, "Analytical and Experimental Studies on Fatigue Life Prediction of Steel and Composite Multi-leaf Spring for Light Passenger Vehicles Using Life Data Analysis", ISSN 1392-1320 MATERIALS SCIENCE (MEDŽIAGOTYRA). Vol. 13, No. 2. 2007

[15] D.Shilpa, B.Jitendra, "Mono composite leaf spring for light weight vehicle - design, End joint analysis and testing", ISSN - 23206136, IJOAASE Volume 1 issue $3 \mathrm{~S} / 2013$

[16] M. M. Patunkar1, D. R. Dolas, "Modelling and Analysis of Composite Leaf Spring under theStatic Load Condition by using FEA", International Journal of Mechanical \& Industrial Engineering, Volume 1 Issue 1-2011

[17] Prabhakar, Shah, Rao and Song, "Mechanical and thermal properties of epoxy composites reinforced with waste peanut shell powder as a bio-filler." Fibers and Polymers (2015) 1119-1124

[18] Jearanaisilawong, Eahkanong, Phungsara and Manonukul. "Determination of in-plane elastic properties of rice husk composite." Materials and Design 76 (2015) 55-63

[19] Militky and Jabbar, "Comparative evaluation of fiber treatments on the creep behaviour of jute/green epoxy composites." Composites Part B 80 (2015) 361-368

[20] Braga and Magalhaes, "Analysis of the mechanical and thermal properties of jute and glass fiber as reinforcement epoxy hybrid composites." Materials Science and Engineering C 56 (2015) 269-273

[21] Maples, Wakefield, Robinson and Bismarck, "High performance carbon fibre reinforced epoxy composites with controllable stiffness." Composites Science and Technology 105 (2014) 134-143 
[22] Li, M-C., Zhang, Y., Cho, U.R., Mechanical, Thermal and Friction Properties of Rice Bran Carbon/Nitrile Rubber Composites: Influence of Particle Size and Loading, Materials and Design (2014), doi:http://dx.doi.org/10.1016/j.matdes.2014.06.032

[23] Shibata, Yamaguchi and Hokkirigawa, "Tribological behavior of RH ceramics made from rice husk sliding against stainless steel, alumina, silicon carbide, and silicon nitride.” Tribology International 73 (2014) 187-194

[24] Rout and Satapathy, "Study on mechanical and tribo-performance of rice-husk filled glass-epoxy hybrid composites." Materials and Design 41 (2012) 131-141

[25] Biswas and Satapathy, "A comparative study on erosion characteristics of red mud filled bamboo-epoxy and glass-epoxy composites." Materials and Design 31 (2010) 1752-1767

[26] Guermazi, N., Haddar, N., Elleuch, K., Ayedi, H.F., Investigations on the fabrication and the characterization of glass/epoxy, carbon/epoxy and hybrid composites used in the reinforcement and the repair of aeronautic structures, Materials and Design (2013), doi: http://dx.doi.org/10.1016/j.matdes.2013.11.043 